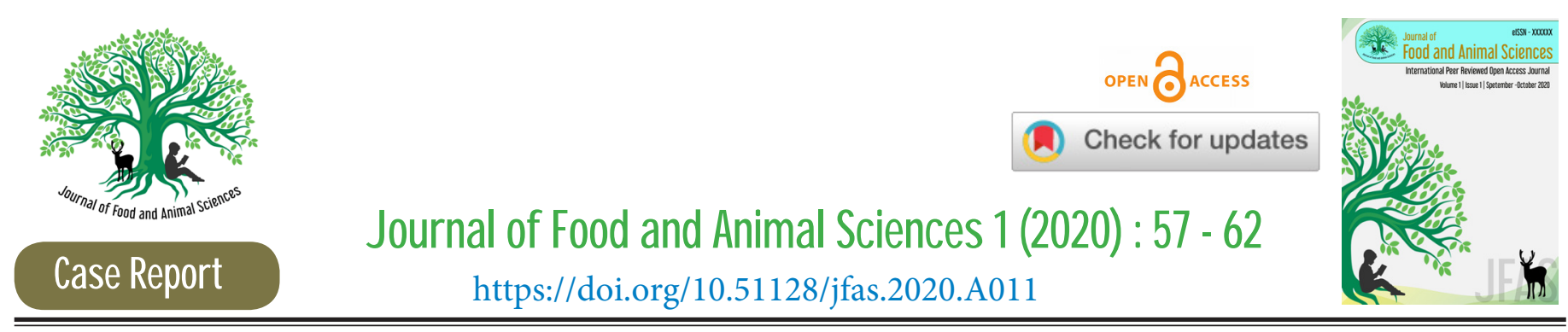

\title{
Surgical management of ileocolic intussusception in a German shepherd dog
}

\author{
C. K. Faslu Rahman ${ }^{a}$ Gokul Raj S. ${ }^{b}$, Khan Sharun ${ }^{(\mathbb{D}}$ \\ ${ }^{a}$ Division of Livestock Products Technology, ICAR- Indian Veterinary Research Institute, Izatnagar, Bareilly, Uttar \\ Pradesh \\ ${ }^{\mathbf{b}}$ Department of Veterinary Surgery and Radiology, College of Veterinary Sciences and Animal Husbandry, Selesih, \\ Aizawl, Mizoram \\ CDivision of Surgery, ICAR-Indian Veterinary Research Institute, Izatnagar, Bareilly, Uttar Pradesh
}

Corresponding author: C. K. Faslu Rahman | email: ckfaslurahman@gmail.com

Co-authors: GRS: drgokulrajvet@gmail.com; KS: sharunkhansk@gmail.com

Received: 23-08-2020, Accepted: 29-09-2020, Published online: 17-10-2020

\begin{abstract}
Intussusception occurs when excessive peristaltic motility forces one segment of the intestine into another slightly larger part of the intestine. The incidence of intussusception is more in German shepherd dogs. A sixmonth old German shepherd dog weighing $17 \mathrm{~kg}$ was presented with a history of anorexia, vomiting, diarrhoea, and lethargy for the past 7 days. Clinical examination revealed a congested conjunctival mucous membrane, bounding pulse and tachycardia. Abdominal palpation evinced pain and a bunch of coiled sausage shaped mass was identified during deep palpation. Abdominal ultrasonography revealed bulls eye appearance in the intestine confirming the occurrence of intussusception. Pre-operatively, the animal was hydrated and stabilized with intravenous fluids. Prophylactic antibiotic therapy using ceftriaxone was given at a dose rate of $25 \mathrm{mg}$ per $\mathrm{kg}$ bodyweight and pre-emptive analgesia with meloxicam at a dose rate of $0.2 \mathrm{mg}$ per $\mathrm{kg}$ bodyweight was also given. Emergency laparotomy was performed under general anaesthesia maintained with isoflurane. A $20 \mathrm{~cm}$ long necrosed irreducible intestinal segment was identified. The necrosed loop was resected after ligating the mesenteric vessels. The cut ends of the intestine being uneven, was cut at right angles and the smaller segment was further cut at an oblique angle to correct the disparity in the lumen size. End to end anastomosis was performed using polydioxanone suture in a simple continues pattern. The abdominal cavity was lavaged with normal saline. Laparotomy wound was closed in a routine pattern. Post operatively, the dog was treated using fluids, antibiotics, and analgesics for seven days. The owner was advised to give easily digestible liquid diet in small quantities from fourth day onwards and gradually shift to normal food. The skin sutures were removed on 10th post-operative day and the animal made an uneventful recovery.
\end{abstract}

Keywords: Ultrasonography, Intestinal telescoping, Resection, Anastomosis, Surgical management, Deworming

\footnotetext{
doi: https://doi.org/10.51128/jfas.2020.A011 / How to cite this article: Faslu Rahman C.K., Raj S.G.,, Sharun, K. 2020. Surgical management of ileocolic intussusception in a German shepherd dog. Journal of Food and Animal Sciences, 01(01): 57 - 62.

Copyright: Faslu Rahman et al. Open Access. This article is distributed under the terms of the Creative Commons Attribution 4.0 International License (http://creativecommons.org/licenses/by/4.0/), which permits unrestricted use, distribution, and reproduction in any medium, provided you give appropriate credit to the original author(s) and the source, provide a link to the Creative Commons license, and indicate if changes were made. The Creative Commons Public Domain Dedication waiver (http://creativecommons.org/publicdomain/zero/1.0/) applies to the data made available in this article, unless otherwise stated.
} 


\section{Introduction}

Intussusception can be defined as prolapse of one part of the intestine into the lumen of an immediately adjoining part (Applewhite, 2001). An intussusception consists of intussusceptum (i.e., the invaginated segment), intussuscipiens (i.e., the invaginating segment), apex (the junction between the entering and the returning segments), and neck (the junction of the returning segment and the intussuscipiens) (Lewis and Ellison, 1987; Kovak and Buriko, 2015). The condition is common in dogs and cats, especially in young ones (Patsikas et al., 2019). The predisposing factors for the intussusception can be multiple, like intestinal parasitism, bacterial and viral enteritis, intestinal foreign bodies, prior abdominal surgery, intestinal neoplasia, and extra/intra-luminal mass lesions that cause intestinal motility disturbances (Applewhite et al., 2002; Colomé et al., 2006).

The invagination of intestine usually happens in the direction of peristaltic movement and rarely in the opposite direction (Lewis and Ellison, 1987). Intussusception can be classified according to the location like entero-colic (ileo-colic), caecocolic, entero-enteric, duodeno-gastric, and gastrooesophageal. It is also classified as high intussusception (proximal to the jejunum) and low intussusception (distal to the duodenum) (Dixon, 2004). In animals, intussusceptions commonly occur at ileocecocolic junction (Wilson and Burt, 1974; Levitt and Bauer, 1992; Fossum et al., 2002). However, intussusceptions of oesophagus, stomach, and colon are also reported in dogs (Pass and Lennox, 1972).

Diagnosis of intussusception can be done by palpation, radiography, ultrasonography, and computed tomography (Patsikas et al, 2019). Ultrasonography is considered as the accurate diagnostic method for the diagnosis of intestinal intussusception in humans and animals (Penninck and Anjou, 2008). The 'target sign' or 'Bull's eye' appearance is a characteristic sign of intussusception on ultrasonography. It may be due to compression of the mucosal and serosal surfaces and intestinal oedema (Lee et al., 2005). Manual reduction can be adopted for correction of the condition if the intussusception is reducible, otherwise, resection of affected portion and enteroanastomosis is needed for correction. This case report describes in detail about small intestinal intussusception in a six-month-old German shepherd dog, outlines successful treatment, and depicts the surgical procedure to prevent its recurrence.

\section{Case history and diagnosis}

A six-month-old German shepherd dog weighing $17 \mathrm{~kg}$ was presented with a history of anorexia, vomiting, diarrhoea and lethargy for the past 7 days. Clinical examination revealed congested conjunctival mucous membrane, bounding pulse, and tachycardia. Fecal sample examination revealed the presence of Toxocara Spp ova. Palpation evinced pain and a bunch of coiled sausage shaped mass was palpable at the mid caudal abdominal region. Ultrasonographic examination of the hard portion identified multiple concentric hyperechoic and hypoechoic rings known as 'bulls eye/target sign' (Fig. 1). Longitudinal ultrasonographic scan shown a sausage-shaped mass with folded layers of intestinal wall. The history, clinical, and ultrasonographic findings were suggestive of intestinal intussusception.

\section{Surgical management}

It was decided to manage the case surgically, and the patient was prepared for surgical procedure. Pre operatively, the animal was hydrated and stabilized with intravenous fluids. Prophylactic antibiotic therapy was initiated with ceftriaxone at the dose rate of $25 \mathrm{mg}$ per $\mathrm{kg}$ body weight and pre-emptive analgesia with meloxicam at the dose rate of $0.2 \mathrm{mg}$ per $\mathrm{kg}$ body weight was also given. The animal was given pre anesthetic drugs, Acepromazine at the dose rate of $0.05 \mathrm{mg} / \mathrm{kg}$ body weight (intramuscular), Butorphanol at $0.4 \mathrm{mg} / \mathrm{kg}$ (intravenous), and Midazolam at 0.2 $\mathrm{mg} / \mathrm{kg}$ (intramuscular). The anesthesia was induced by Ketamine at $5 \mathrm{mg} / \mathrm{kg}$ intravenously to effect. The anaesthesia was further maintained using isoflurane inhalant anesthesia. The animal was positioned in dorsal recumbency for ventral midline celiotomy and was prepared for aseptic surgery by scrubbing with povidone-iodine $(0.75 \% \mathrm{w} / \mathrm{v})$ surgical scrub.

The peritoneal cavity was opened by giving an incision on the skin, subcutaneous tissue, at linea alba and the peritoneum. On exploration, the intussusception was found to be on ileo-colic junction. An approximately $20 \mathrm{~cm}$ long necrosed intestine which was irreducible was identified (Fig. 2). Atraumatic clamps were applied on proximal and distal ends before resection (Fig. 3b). The necrosed loop was resected after ligating the mesenteric blood vessels (Fig. 3a). End to end anastomosis was performed using 4/0 polydioxanone suture in simple continuous pattern (Fig. 4a). The dilated segment was cut at right angles and the smaller segment at an oblique angle to correct 

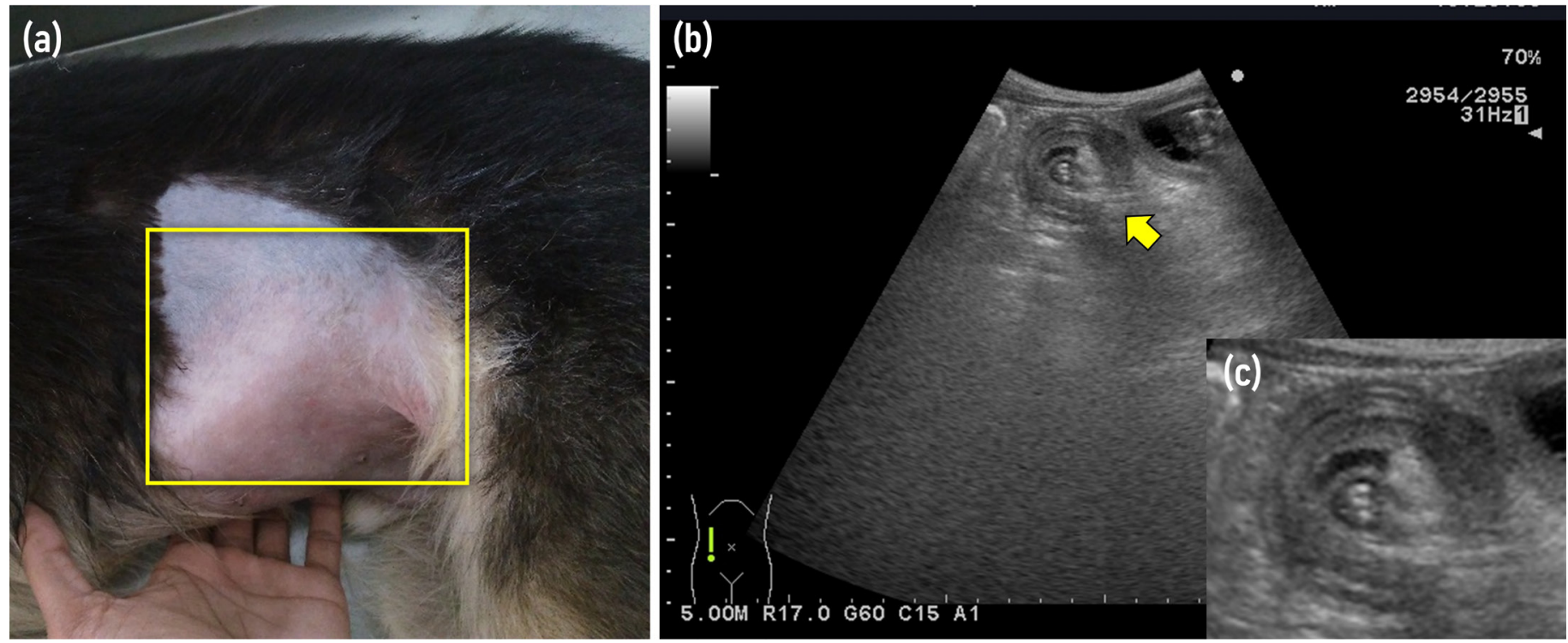

Figure 1: (a) Area of palpation at the mid caudal abdominal region where the bunch of coiled sausage shaped mass was observed. (b) and (c) Bull's eye/Target sign on ultrasonography.
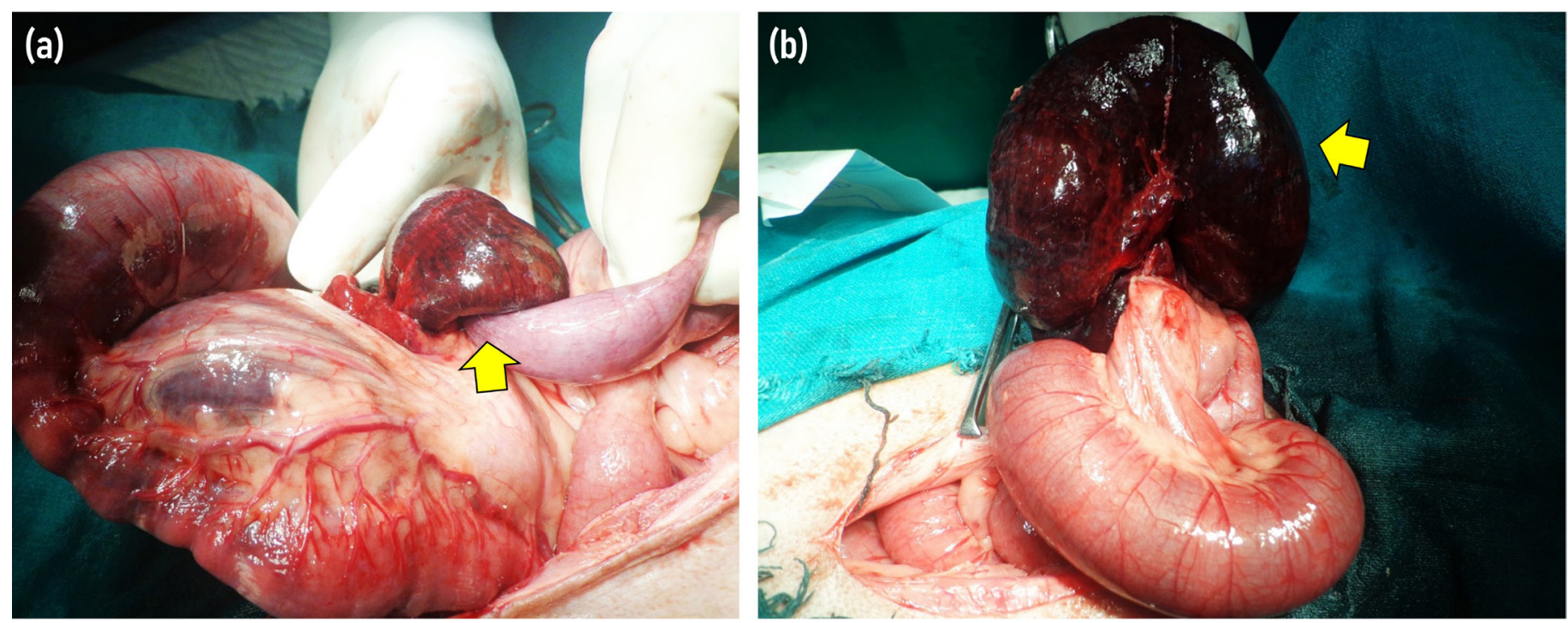

Figure 2: (a) The area of intussusception where the ileum (intussusceptum) invaginated into caecum (intussuscipiens). (b) The necrosed are of intestine that was resected.

the disparity in lumen size as the opposing ends were uneven (Fig. 3d). The abdominal cavity was lavaged with normal saline. Laparotomy wound was closed in standard procedure. Post operatively, the dog was treated with fluids, antibiotics, and analgesics for seven days. The owner was advised to give easily digestible liquid diet in small quantities from fourth day onwards and gradually shift to normal food. The skin sutures were removed on $10^{\text {th }}$ post-operative day and the animal made an uneventful recovery.

\section{Discussion}

The incidence of intussusceptions is more common in German shepherd dogs (Sivasankar, 2000). Intussusceptions occurs most commonly in younger dogs below 6 months of age (Weaver, 1977; Lewis and Ellison, 1987). The most common clinical signs of intussusception in dogs are anorexia, vomiting and diarrhoea. Prevalence of Toxocara canis in younger dogs of age below 6-months are much higher in case of stray dogs $(62.79 \%)$ and owned dogs (41.74\%) (Shukla et al., 2007; Swai et al., 2010). This high prevalence of parasites might have contributed to the increased rate of intussusceptions in puppies. Presence of parasites in the intestine leads to abnormal peristaltic movement and results in telescoping of intestinal segment into the adjacent parts of intestine. In this case, the improper deworming of animal might have resulted in toxocariasis further resulting in ileo-colic intussusception. 

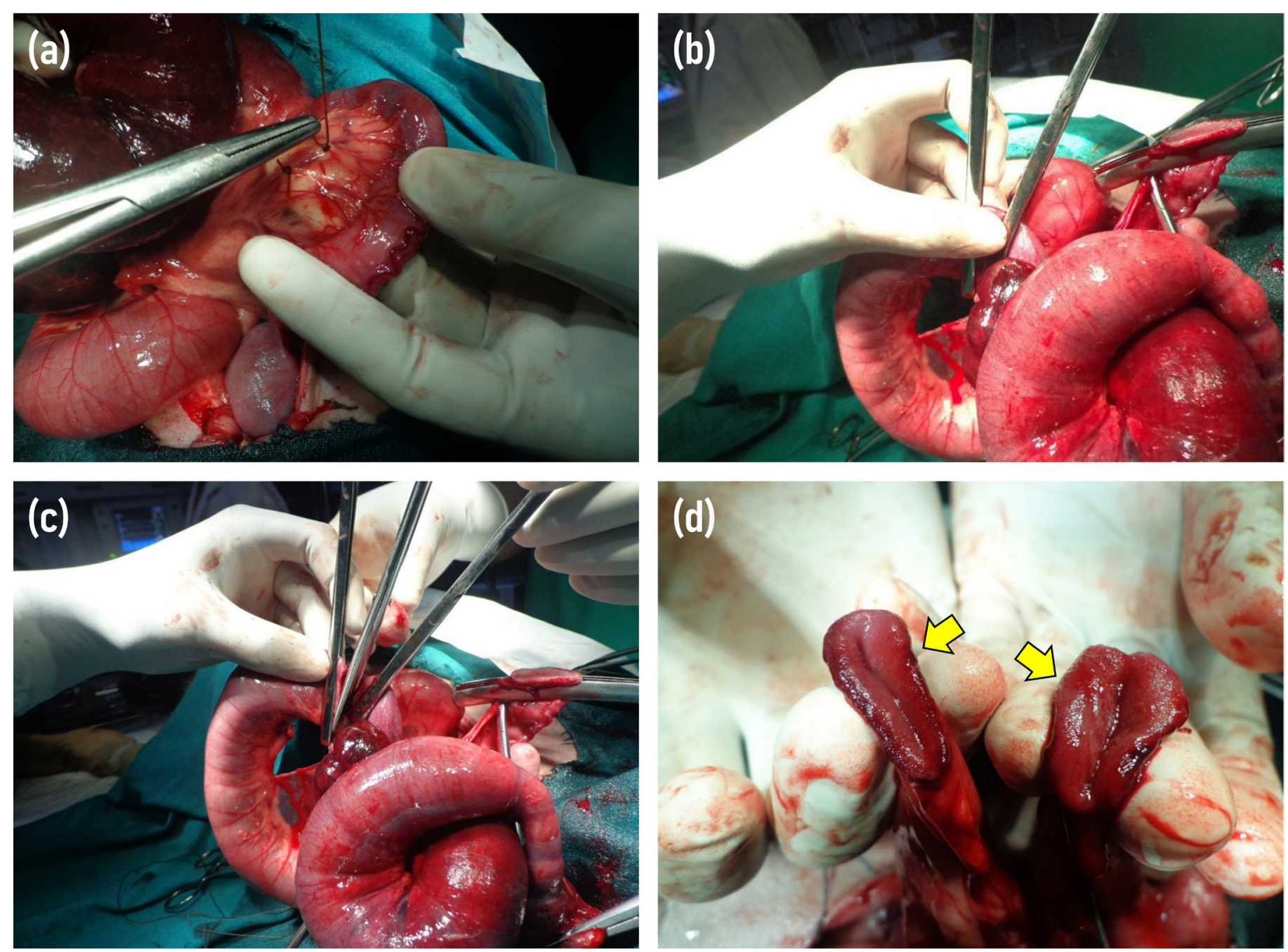

Figure 3: (a) Mesenteric blood vessels were ligated to check bleeding while resection. (b) The clamps were applied on the proximal and distal ends of necrosed intestinal segments. (c) Resection of the necrosed intestinal segment. (d) The dilated segment was cut at right angles and the smaller segment at an oblique angle to correct the disparity in the lumen size.
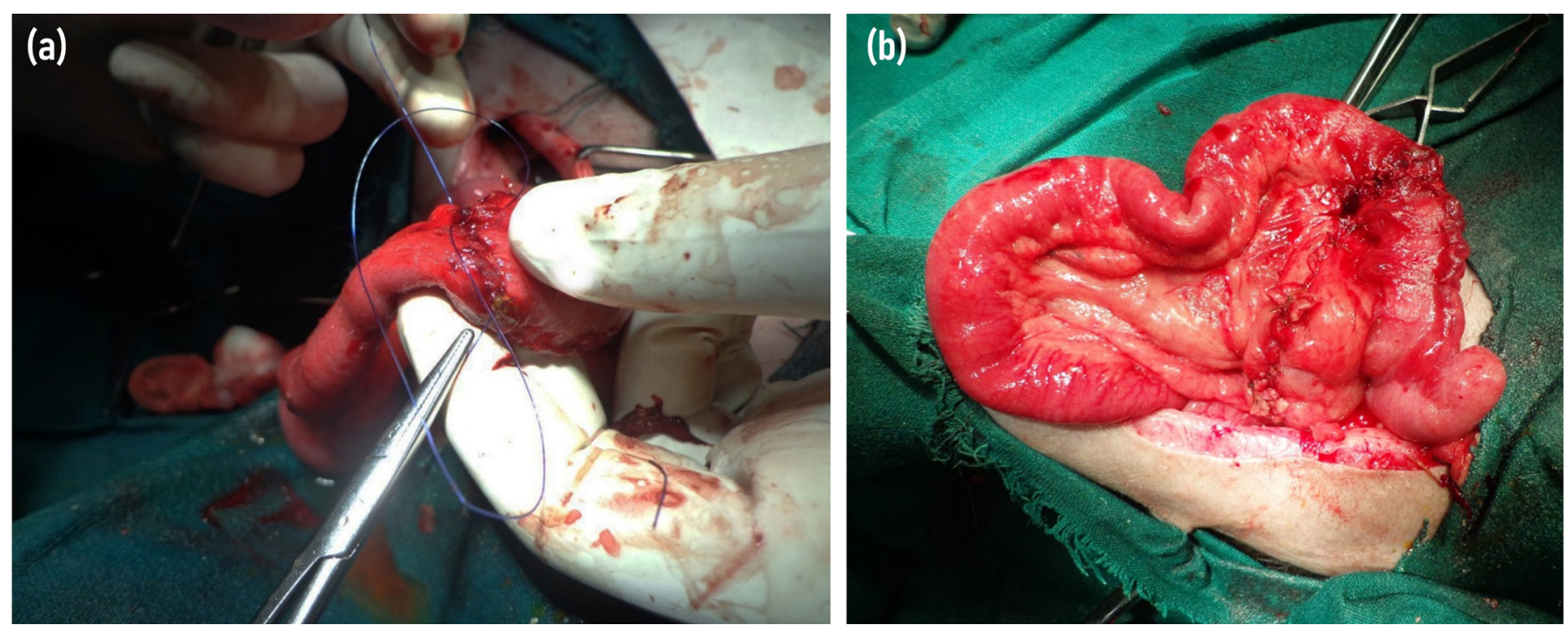

Figure 4: (a) Suturing of proximal and distal ends of the intestine (b) Intestine and mesentery after suturing. 
Abdominal palpation is a helpful tool for the identification of intussusceptions. The presence of a tubular structure can be felt at the cranial or mid abdomen during palpation. Plain radiography cannot always differentiate the intestinal obstruction. if there is complete obstruction of intestine, at the region of intussusception, gas filled intestinal loops can be visualised proximal to the obstructed site. Contrast radiography of intestine by using barium sulphate can be done to confirm the intestinal obstruction (Wilson and Burt, 1974). However, in this case, animal was very weak so the barium contrast radiography could not be performed. The best method for the differentiation of intussusceptions is the abdominal ultrasonography (Manczur and Voros, 2000). In ultrasonographic examination, intussusception can be visualised as concentric rings in transverse section and in longitudinal section multiple hyper and hypo echoic parallel lines are seen (Patsikas et al., 2003).

\section{Conclusion}

Complication of intussusception include ischemia and necrosis of intestinal segments. There will be obstruction of blood vessel at the site of intussusception and initially intestine will be swollen and congested later the condition progress and adhesion of intestinal segment occurs due to fibrinous exudation from the serosal layer of the intestine. As the obstruction of arterial blood flow continues, it will lead to the necrosis of the affected part. Enterectomy can be performed for the removal of non-viable region of intestinal segment and end to end anastomosis can be performed. This case report points out the importance of proper deworming and hence the prevention of life-threatening intussusception in puppies as well as timely diagnosis along with proper surgical intervention will be help to save the life of the animal.

\section{Authorship contribution statement}

C. K. Faslu Rahman: Conceptualization, Methodology, Investigation, Writing - original draft, Gokul Raj S: Writing - original draft, Khan Sharun: Writing - review \& editing.

\section{Acknowledgments}

All the authors acknowledge and thank their respective Institutes and Universities.

\section{Funding}

There is no substantial funding to be stated.

\section{Declaration of Competing Interest}

All authors declare that there exist no commercial or financial relationships that could, in any way, lead to a potential conflict of interest.

\section{References}

Applewhite, A.A., Cornell, K.K., Selcer, B.A. 2002. Diagnosis and treatment of intussusceptions in dogs. Compendium on continuing education for the practising veterinarian-north American edition. 24(2):110-27.

Applewhite, A.A., Cornell, K.K., Selcer, B.A. 2001. Pylorogastric intussusception in the dog: a case report and literature review. Journal of the American Animal Hospital Association. 37(3):23843.

Brown, D.C. 2012. Small intestine. In: Tobias, K.M. (Ed.) Veterinary Surgery Small Animal, 1st edn. Missouri: Elsevier Saunders.1513-1541.

Colomé, L.M., Contesini, E.A., de Castro Beck, C.A., Ferreira, M.P., Beheregaray, W.K., Júnior, A,R. and Martins, C.G. 2006. Intussuscepção jejunoileal dupla em um cão. Acta Scientiae Veterinariae. 34(2):225-8.

Dixon, B.C. 2004. In: Tilley, L.P. and Smith, F. W. K. Jr. (Eds) The 5-minute veterinary consult Canine and Feline. 3rd ed., Lippincott Williams and Wilkins. pp:721-722

Fossum, T. W.,C. S. Hedlund. D.A. Hulse, A. L. Johnson, H. B. Seim, M D. Willard, and G. L. Carroll 2002. Small Animal Surgery, Elsevier Science company. pp:390-391.

Kovak. J.J., Buriko, K. 2015. Intussusception. Small Animal Surgical Emergencies. 9:43-8.

Lee, H., Yeon, S., Lee, H., Chang, D., Eom, K., Yoon, J., Choi, H. and Lee Y. 2005. Ultrasonographic diagnosis-pylorogastric intussusception in a dog. Veterinary Radiology \& Ultrasound. 46(4):317-318.

Levitt, L. and Bauer, M.S. 1992. Intussusception in dogs and cats: A review of 36 cases. The Canadian Veterinary Journal. 33(10):660.

Lewis, D.D. and Ellison, G.W. 1987. Intussusception in dogs and cats. Compend Contin Educ Pract Vet. 9:523-33.

Manczur, F. 2000. Gastrointestinal ultrasonography of the dog: a review of 265 cases (1996-1998). Acta Veterinaria Hungarica. 48(1):9-21.

Pass, M.A. and Lennox, W.J. 1972. Three cases of 
intussusception of the small intestine in the dog. The Canadian Veterinary Journal. 13(11):266.

Patsikas, M.N., Jakovljevic, S., Moustardas, N., Papazoglou, L.G., Kazakos, G.M. and Dessiris, A.K. 2003. Ultrasonographic signs of intestinal intussusception associated with acute enteritis or gastroenteritis in 19 young dogs. Journal of the American Animal Hospital Association. 39(1):5766.

Patsikas, M.N., Papazoglou, L.G. and Paraskevas, G.K. 2019. Current Views in the Diagnosis and Treatment of Intestinal Intussusception. Topics in Companion Animal Medicine. 37:100360.

Penninck, D.G.and d'Anjou,M.A.2008. Gastrointestinal tract. Ames, Iowa: Blackwell publishing.

Shukla, R., Giraldo, P., Kraliz, A., Finnigan, M. and Sanchez, A.L. 2006. Cryptosporidium spp. and other zoonotic enteric parasites in a sample of domestic dogs and cats in the Niagara region of Ontario. The Canadian Veterinary Journal. 47(12): 1179 .

Sivasankar, M. 2000. Recurrent intussusception in a 14-month-old, spayed, female German shepherd cross. The Canadian Veterinary Journal. 41(5):407.

Swai, E.S., Kaaya, E.J., Mshanga, D.A. and Mbise, E.W. 2010. A survey on gastro-intestinal parasites of non-descript dogs in and around Arusha Municipality, Tanzania. International Journal of Animal and Veterinary Advances. 2(3):63-7.

Weaver,A.D. 1977. Canine intestinal intussusception. The Veterinary record. 100(25):524.

Wilson, G.P., Burt, J.K.1974. Intussusception in the dog and cat: a review of 45 cases. Journal of the American Veterinary Medical Association. 164(5):515. 